\title{
La evolución de la Cirugía, un concepto unido a la investigación ya la educación permanente del cirujano plástico
}

\section{The evolution of Surgery, a concept linked to the research and permanent education of the plastic surgeon}

Fernando MOLINA

Profesor de Cirugía Plástica

Presidente de la Fundación Fernando Ortiz Monasterio

Director del Área Científica de FILACP 2018-2020

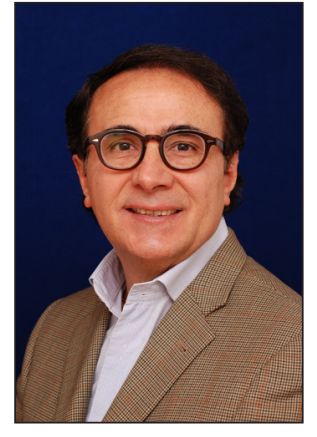

Molina, F.
El proceso de impartir educación médica a cirujanos y residentes de la especialidad ha permanecido prácticamente sin cambios durante décadas. Sus apoyos didácticos son conferencias y clases monotemáticas, llevadas a cabo en sesiones de pequeños grupos, donde frecuentemente la falta de participación y el desacoplamiento se puede observar.

Educar al cirujano ya formado y con años de experiencia profesional es un proceso aún más complejo. Existen relativamente pocos análisis serios sobre la eficacia del proceso enseñanza-aprendizaje, especialmente escrutinios con pruebas efectuadas a la audiencia y estos resultados compararlos con los métodos tradicionales.

Hoy en día, existen varios motivos para producir una educación médica eficaz y contemporánea. Incluso la misma, puede resultar personalizada y moderna. Los avances exponenciales en tecnología han tenido en los métodos educativos un gran factor de impacto. Un cirujano experimentado requiere solo afinar sus conocimientos teóricos e incorporar a su práctica los avances de la investigación. En técnica quirúrgica, requiere poder observar la minucia de una maniobra o el "truco" técnico para mejorar un procedimiento. Los paneles de expertos con amplias discusiones, las videoconfrontaciones, los cursos con disecciones en cadáveres y los sistemas digitales con simulaciones quirúrgicas, han venido reemplazando a las conferencias, los trabajos libres repetitivos y las reiterativas exposiciones de un mismo ponente.

Sin duda, durante el desarrollo de un congreso médico la incorporación de sistemas digitales complementa los métodos tradicionales de enseñanza, produciendo un proceso más dinámico e interactivo.

Debo mencionar que la incorporación de recursos digitales y de las cirugías de simulación han resuelto graves limitaciones en la educación quirúrgica, haciendo que las técnicas se comprendan de una forma más clara y fácil. Desafortunadamente todas estas modernas herramientas, hasta ahora, no se han desarrollado en nuestra especialidad tan ampliamente como en otras especialidades médico-quirúrgicas. Estoy seguro de que en un futuro podremos disponer de más simuladores quirúrgicos altamente promisorios que ofrecerán el desarrollo de habilidades quirúrgicas de realidad virtual y la recreación de ambientes quirúrgicos tridimensionales. Los avances en computación, en internet y la creciente capacidad de los teléfonos móviles inteligentes, dan oportunidad a los usuarios de utilizar fácilmente información digital con un alto rendimiento.

Mi experiencia como profesor de Cirugía Plástica me estimula a aprovechar las ventajas de estas nuevas estrategias educacionales y obtener óptimos resultados en el alumno en un tiempo más corto. Además, se supera el concepto de bi-dimensión de un texto con esquemas, incorporando a su educación la tri-dimensión de un campo quirúrgico virtual, o bien de uno real.

Además hoy día, el cirujano plástico conecta con pacientes y público utilizando medios digitales. Ya sea para la difícil tarea de educarlos, de reafirmar su liderazgo profesional en la Cirugía Plástica o bien para atraerlos como pacientes. El 23\% de la población mundial utiliza Facebook al menos una vez por mes y hoy las redes sociales se han convertido en una herramienta indispensable en la educación del paciente. Para el cirujano moderno representa una gran ventaja interactuar con un paciente ampliamente informado y que conoce en detalle el proceso al que va a someterse, incluidas las posibles complicaciones.

$\mathrm{Y}$ en las mismas redes sociales, poco a poco, las mismas sociedades científicas deberán difundir al público, que luego de que se concluye un entrenamiento formal 
en Cirugía Plástica, algunas veces seguido de un curso específico de alta especialidad, todo profesional debe completar cada 5 o 10 años un proceso de recertificación como especialista. Esto incluye obtener educación continua, actualizar su entrenamiento, potenciar su competencia profesional y mantener su grado de licenciatura universitaria. Estas capacidades profesionales actualizadas van a garantizar seguridad para el paciente y automáticamente pondrán una distancia mayor entre el cirujano plástico y otros profesionales que practican Cirugía Plástica de manera irresponsable.

Sobra mencionar que existen diversos motivos para modificar la apariencia física con Cirugía Plástica. Necesidades reconstructivas, deformidades congénitas, defectos físicos indeseables o razones puramente estéticas. Y por la influencia de los medios masivos de comunicación, habrá que agregar las costumbres sociales contemporáneas, la importancia hoy en la apariencia de una persona y las reglas de criterios estéticos comunes dentro de un grupo social, étnico o geográfico. Terrenos en donde la incrementada accesibilidad a la Cirugía Estética, apoyada por una mejor economía familiar y la creencia común de que lo natural es totalmente mejorable y de que la enfermedad y la edad pueden evitarse o posponerse, y aún más, pueden razonablemente omitirse.

No quiero concluir sin mencionar las contribuciones académicas de la mujer como cirujano plástico. Su buen trabajo, sus tareas y su talento se han incrementado substancialmente en las últimas décadas y todas constituyen lecciones fecundas y grandes aportaciones a la ciencia o bien algunas otras, pertenecen a la educación de todos los días. Una forma de darnos cuenta es la gran productiva femenina en investigación y sus publicaciones como primer autor, que han aumentado cinco veces desde los años setenta hasta el día de hoy. Este interesante cambio ha demostrado que en la mujer cirujano no existía solamente una falta de ambición profesional, sino que ya se ha superado la etapa de la diferencia en experiencias académicas, enfatizada por un pobre apoyo institucional y pocas oportunidades de trabajo como líderes.

Hoy ya está desechada esa absurda teoría de la "congruencia de roles", que postula que primitivas partes de nuestro cerebro dictan la idea sobre los roles y el género. Posiblemente este primitivo concepto de patrón social ha sido el motor para hoy tener a grandes mujeres líderes en la Cirugía Plástica. Y aún más, hoy sabemos que con su elección de responsabilidades y de su trabajo, al igual que sucede en el hombre, son muy felices. Hecho que demuestra el bien equilibrado balance entre trabajo y vida. Trabajemos todos juntos en la creatividad, olvidemos las prácticas tradicionales ya obsoletas, e influenciemos con esta mística a gente joven en este maravilloso ejercicio de compartir conocimientos, de investigar en cosas no bien resueltas y de agregar la excelencia a nuestro trabajo todos los días.

fermomo57@hotmail.com

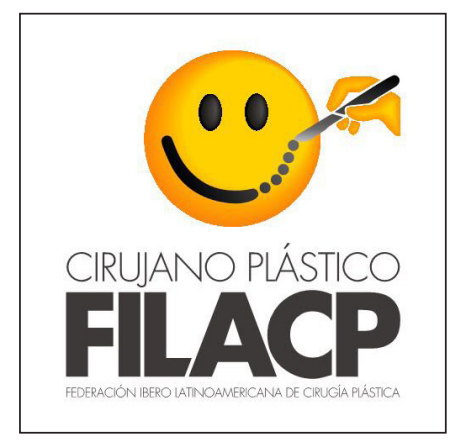

